CASE REPORT

\title{
Non-invasive diagnosis of tracheobronchomalacia using a modified ventilation radioisotope lung scan
}

\author{
A Gour, M J Peters, I Gordon, A J Petros
}

Arch Dis Child 2003;88:1122-1123

The use of radionuclide ventilation lung scan to characterise the physiological effects of tracheobronchomalacia is a novel application of this non-invasive technique. In the reported case the right upper lobe was found to be not ventilated below a pressure of $20 \mathrm{~cm} \mathrm{H}$ O despite evidence from a dynamic tracheobronchogram of the right upper lobe bronchus opening at the lower pressure of $15 \mathrm{~cm} \mathrm{H}_{2} \mathrm{O}$.

$\mathrm{T}$ racheobronchomalacia (TBM) is an important cause of morbidity resulting in prolonged stay on the paediatric intensive care unit (PICU). It is characterised by weakness of the tracheobronchial walls and supportive cartilage. It is occurs as primary TBM in isolation, ${ }^{1}$ usually following prolonged intubation in preterm babies, or in association with congenital heart disease. Secondary causes include gastro-oesophageal reflux and tracheo-oesophageal fistula repair. Tracheobronchogram $(\mathrm{TBG})^{23}$ and rigid or flexible bronchoscopy are the current methods of diagnosis of TBM. We report a case which highlights the value of a modified radionuclide ventilation scan in a case of TBM which was incompletely characterised by TBG.

\section{CASE REPORT}

A term baby girl born to unrelated healthy parents with normal APGARS at birth developed respiratory distress and required endotracheal intubation and ventilation at 4 hours of life. Chest $x$ ray (fig 1 ) revealed a thoracic scoliosis, thoracic hemi-vertebrae from T2-8, absent second to seventh ribs on the left, and dextrocardia. Echocardiography confirmed dextrocardia and a structurally normal heart. Ultrasound of the abdomen reported an absent left kidney. Chromosome analysis was normal. A review of the literature revealed no previous report associating this kind of combination with tracheobronchomalacia.

A computed tomography scan of the chest revealed left lung hypoplasia and an adequate sized right lung with normal attenuation and normal vascular distribution. It also confirmed the presence of hemi-vertebral agenesis with only cartilaginous remnants of ribs on the left. A magnetic resonance image of the chest also showed rudimentary ribs in the apical portion of the left hemi-thorax and reported smaller left lung volume relative to the right lung, when fully expanded. Two trials of weaning from mechanical ventilation and extubation were unsuccessful.

Although paradoxical movement of the chest wall had not been a major feature of the respiratory failure, following the failed extubations a plaster cast jacket was fashioned to try and improve the lung mechanics by reducing flail movement of the left chest wall. ${ }^{4}$ However, a further attempt at extubation with the chest wall splinted also resulted in acute failure. As a consequence of the immediate deterioration, tracheobronchomalacia was suspected. A dynamic TBG with incremental levels of peak end expiratory pressures (PEEP) was performed to determine the opening pressures of any malacic segments detected. The TBG confirmed the presence of TBM with opening pressures at the trachea of $10 \mathrm{~cm} \mathrm{H}_{2} \mathrm{O}$ and for both bronchi of $10-15 \mathrm{~cm} \mathrm{H}_{2} \mathrm{O}$ (fig 2).

A diagnostic isotope ventilation lung scan using krypton $\left(\mathrm{Kr}^{81 \mathrm{~m}}\right)$ scan was performed to assess the degree of left pulmonary hypoplasia. This revealed no isotope present on the ventilation scan in the area of the right upper lobe. Only when a PEEP of $15 \mathrm{~cm} \mathrm{H}_{2} \mathrm{O}$ was applied did the right upper lobe region become poorly ventilated. Isotope intensity was only equal to the left upper lobe area when a PEEP of $20 \mathrm{~cm} \mathrm{H}_{2} \mathrm{O}$ was applied. This localised segment of severe bronchomalacia, involving the peripheral part of the airways was thought to be contributing to respiratory failure. The baby was successfully ventilated with continuous positive airway pressure of $20 \mathrm{~cm} \mathrm{H}_{2} \mathrm{O}$ for one week. Our proposed treatment plans included a tracheostomy and mechanical ventilation with high levels of PEEP of $15-20 \mathrm{~cm} \mathrm{H}_{2} \mathrm{O}$, initially for six months; the trachea and bronchi would then be reassessed to gauge any improvement. ${ }^{5}$ However, her condition deteriorated during the course of this week and she died with sepsis.

\section{DISCUSSION}

The use of radionuclide ventilation lung scan to characterise the physiological effects of malacia of the tracheobronchial tree, is a novel application of this non-invasive technique. In this case, krypton lung scan with variable levels of PEEP proved to be a very helpful technique in characterising the

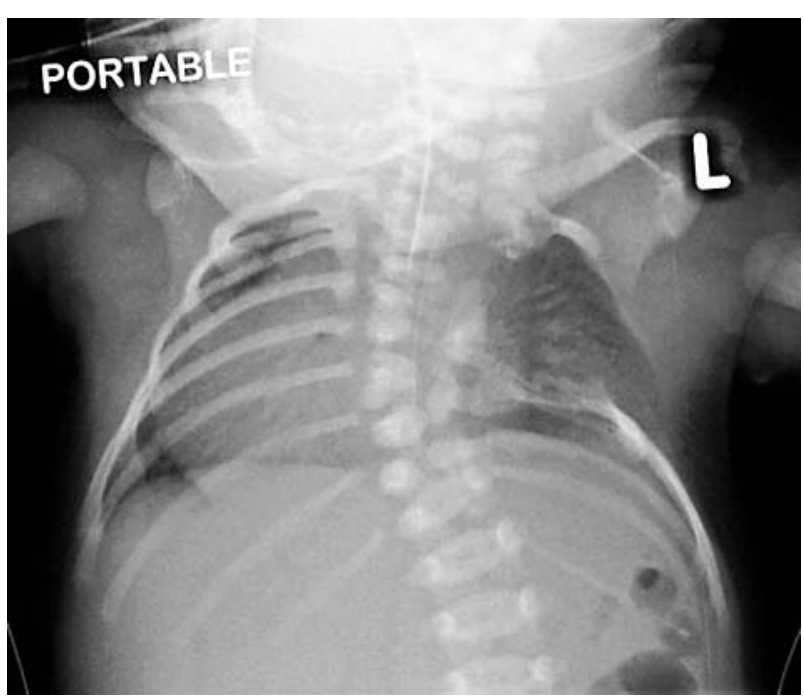

Figure 1 Chest radiograph showing dextrocardia, scoliosis, and absence of 2 nd -7 th ribs on the left. 


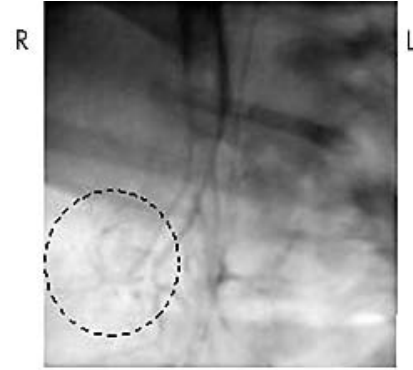

PEEP 10

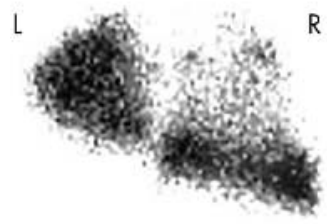

PEEP 10

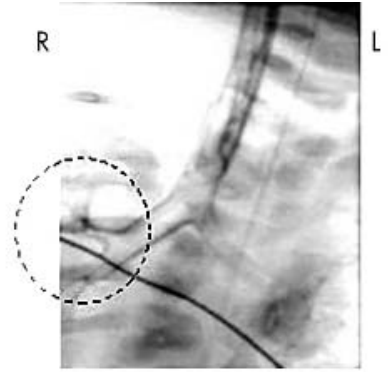

PEEP 15

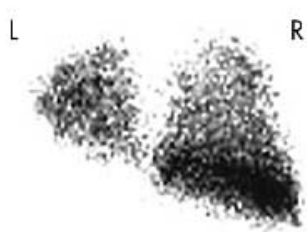

PEEP 15

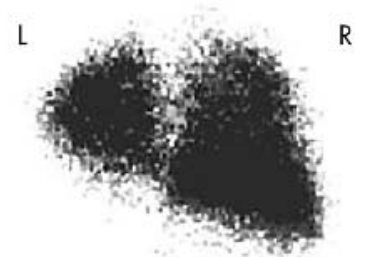

PEEP 20

Figure 2 Upper panel: tracheobronchogram (anterior view) with positive end expiratory pressure (PEEP) of 10 and $15 \mathrm{~cm} \mathrm{H}_{2} \mathrm{O}$. The right main bronchus (dashed circle) only opens at $15 \mathrm{~cm} \mathrm{H}_{2} \mathrm{O}$. Lower panel: isotope ventilation lung scans (posterior view) showing no isotope present on the ventilation scans in the area of the right upper lobe when $10 \mathrm{~cm} \mathrm{H}_{2} \mathrm{O}$ PEEP was applied. Only when a PEEP of $15 \mathrm{~cm} \mathrm{H}_{2} \mathrm{O}$ was applied did the right upper lobe region become poorly ventilated. Isotope intensity was only equal to the left upper lobe area when a PEEP of $20 \mathrm{~cm} \mathrm{H}_{2} \mathrm{O}$ was applied.

defect identified on TBG. It has the advantages of having an extremely low radiation burden and being relatively noninvasive compared to a TBG or rigid bronchoscopy. The modified isotope lung scan appears to offer the advantage of giving an indication of peripheral or localised forms of TBM which may be missed on dynamic TBG.

Not infrequently the opening pressures found on TBG bear no clinical relation to the levels of PEEP required to prevent frequent life threatening episodes of desaturation. Often high levels of PEEP of $20-25 \mathrm{~cm} \mathrm{H}_{2} \mathrm{O}$ at TBG are necessary to open malacic trachea or bronchi. However, on return to conventional ventilation the child only needs $5-20 \mathrm{~cm} \mathrm{H}_{2} \mathrm{O}$ and can be extubated despite high opening pressures on TBG. This conflicting observation and poor correlation between TBG and clinical reality have led us to question the value of TBG and search for another corroborative technique to assess TBM.

In this case the TBG provided a detailed anatomical picture of the airway. However, the radionuclide ventilation scan provided a better understanding of the pressures needed to ventilate all segments of the lungs.

\section{Authors' affiliations}

A Gour, M J Peters, A J Petros, Paediatric Intensive Care Unit, Great Ormond Street Hospital for Children NHS Trust, London, UK

I Gordon, Department of Radiology, Great Ormond Street Hospital for Children NHS Trust, London, UK

Correspondence to: Dr A Petros, PICU, Great Ormond Street Hospital, London WCIN 3JH, UK; petroa@gosh.nhs.uk

Accepted 13 May 2003

\section{REFERENCES}

1 Doull IJ, Mok Q, Tasker RC. Tracheobronchomalacia in preterm infants with chronic lung disease. Arch Dis Child Fetal Neonatal Ed 1997;76:F203-5.

2 Rozycki HJ, Van Houten ML, Elliott GR. Quantitative assessment of intrathoracic airway collapse in infants and children with tracheobronchomalacia. Pediatr Pulmonol 1996;4:241-5.

3 Burden RJ, Shann F, Warwick B, et al. Tracheobronchial malacia and stenosis in children in intensive care: bronchogram help to predict outcome. Thorax 1999:54:51 1-17

4 Loeff DS, Greenwald MI, Young SC, et al. A unique chest wall splint for unilateral agenesis of ribs. J Paediatr Surg 1987;22:1129-31.

5 Panitch HB, Allen JL, Alpert BE, et al. Effects of CPAP on lung mechanics in infants with acquired tracheobronchomalacia. Am J Respir Crit Care Med 1994; 150:1341-6. 